\title{
Estimation of microphytobenthic resuspension fluxes in a shallow lagoon in Hokkaido, Japan
}

\author{
Natsumi Suga ${ }^{1, *}$, Rumiko Kajihara ${ }^{1}$, Seitchiro Shibanuma ${ }^{1}$, Toshiro Yamada $^{2} \&$ \\ SHIGERU MONTANI ${ }^{1}$ \\ ${ }^{1}$ Graduate School of Environmental Science, Hokkaido University, Kitaku, Sapporo, Hokkaido 060-0810, Japan \\ ${ }^{2}$ Nishimuragumi Co., Ltd., 133-1 Sakaemachi, Yubetsu, Monbetsu, Hokkaido 099-6404, Japan
}

Received 1 October 2010; Accepted 13 February 2011

\begin{abstract}
We conducted field sampling in a subarctic shallow lagoon (Hichirippu Lagoon) in the eastern part of Hokkaido, Japan. We investigated the chemical composition of the water column, sediment, and sinking particles collected by the sediment trap. The standing stock of chlorophyll $a(\mathrm{Chl}-a)$ in the water column and surface sediment were 0.4 to 9.3 and 35.9 to $184 \mathrm{mg} \mathrm{m}^{-2}$, respectively. Using stable isotope analysis, the contribution rate of microphytobenthos to the sinking particles was found to range from 63 to $74 \%$. The average Chl- $a$ content in the sinking particles was significantly lower than that of the water column. Our results suggest that the contribution of phytoplankton present in the water column to the Chl- $a$ collected in the traps is likely to be negligible. We assumed that the Chl- $a$ fluxes obtained in this study were microphytobenthic resuspension fluxes. The daily flux of Chl- $a$ accounted for 47.0 to $1,270 \%$ of the total standing stock of Chl- $a$ in the water column. The mean relative percentage of daily Chl- $a$ flux divided by the standing stock of Chl- $a$ in the sediment was $6.5 \%$, which indicates that approximately $7 \%$ of the microphytobenthos present in the sediment was resuspended, and $93 \%$ of the total succeeded at escaping the winnowing action. Although the resuspension phenomenon had little effect on the population of microphytobenthos, the resuspended microphytobenthos had a major impact on the total micro algal biomass in the water column. This is the first direct estimate of microphytobenthic resuspension flux in shallow estuaries.
\end{abstract}

Key words: lagoon, microphytobenthos, resuspension

\section{Introduction}

The role of microphytobenthos in primary production has been studied for the last two decades. Several studies have shown that microphytobenthos are an important food item in coastal areas (Yamaguchi et al., 2009). In shallow areas, resuspension occurs as a result of tidal currents and wave action (Baillie \& Welsh 1980, Lucas et al. 2000). The resuspension phenomenon increases greatly the importance of microphytobenthos, because it makes the cells available not only to benthic grazers but also to filter feeders (Kamermans 1994, Yamaguchi et al. 2006). The estimation of the microphytobenthic resuspension flux is important if our understanding of the coastal ecosystem is to be improved.

To estimate the resuspension flux of sediment particles, several methods have been proposed (Bloesch 1994). One method is the collection of sinking particles by a sediment trap. Oviatt \& Nixon (1975) reported that one problem with

\footnotetext{
* Corresponding author: Natsumi Suga; E-mail, natsumi@fish.hokudai.ac.jp
}

regard to the description of trap collection data is the difficulty of understanding the source of the sinking particles collected in traps. The particles collected in traps may be a mixture of resuspended sediments and freshly sedimented materials. Rosa et al. (1991) estimated the resuspension flux by comparing traps exposed at mid-depth with nearbottom traps. Based on the difference in the traps, the resuspended particle flux can be detected. However, Bloesch (1994) pointed out that it is difficult to find the appropriate reference depth, where resuspension is thought to have no effect on suspended particulate matter in the water column above the traps. Gasith (1976) corrected the resuspension flux based on the difference in the organic content (\%) of the sediment below the trap and the particulate matter in the water column above the traps. This approach will underestimate resuspension flux in cases in which both materials have the same chemical composition (Floderus 1989). In addition, as the focus of these previous studies was limited to the resuspension of particulate matter, the resuspension of microphytobenthos has received less attention. De Jonge 
\& Van Beusekom (1992) estimated the amount of microphytobenthic resuspension based on effective wind speed. Even though it is appropriate to assume that there is a linear relationship between wind speed and resuspended microphytobenthos, previous estimates of microphytobenthic resuspension are therefore not direct measurement.

For the purpose of describing the sources of materials in the ecosystem, the technique of stable isotopes analysis as a method of environmental tracing has become popular recently (Lathja \& Michener 1994). One application commonly used for the evaluation of source contributions to a mixture is the isotope-mixing model. Examples of such evaluations include determining the pollution inputs to the air, soil, and water column, the determination of food sources in animal diets, the evaluation of plant water use at different soil depths, and many others (Phillips et al. 2005). Using a two-source linear mixing model with $\delta^{13} \mathrm{C}$, Kasai et al. (2004) estimated the relative contribution of terrestrial organic matter to estuarine particulate organic matter. Isotope measurement may be helpful in determining the sources of sinking particles collected in traps.

Resuspended microphytobenthos have two meanings in ecosystems. The first is a meaning in the pelagic ecosystems. In the pelagic region, resuspended microphytobenthos have been found to temporarily increase the total microalgae populations in the water column (Shaffer \& Sullivan 1988) and to become an important food item for filter feeders (Kamermans 1994, Yamaguchi et al. 2006). The second is a meaning in the benthic ecosystems. In the benthic region, resuspended microphytobenthos are regarded as the individuals that fail to migrate down into the sediment. Microphytobenthos are characterized by vertical migration behavior. They migrate upward through the sediment toward the light (Perkins 1958, Palmer 1960) or downward to avoid resuspension and to access higher amounts of nutrients (Paterson 1986, Gruendling 1971). Tidal flooding and winnowing action remove aberrant and senescent individuals that fail to migrate down (Kingston \& Gough 2009).We have not found previous studies that discuss the effect of resuspension on primary producers, not only pelagic microalgae but also microphytobenthos, quantitatively.

In this study, we conducted field measurements of microphytobenthic resuspension flux using sediment traps in a lagoon system (Hichirippu Lagoon) in eastern Hokkaido, Japan. This lagoon system is dominated by a tidal current, and its water depth is extremely shallow (Suga et al. 2011). The aims of this study are (1) to verify the tidal resuspension phenomenon in Hichirippu Lagoon, (2) to determine the source of sinking particles collected in traps using several methods including stable isotope analysis, and (3) to discuss the effect of resuspension on primary producers (pelagic microalgae and microphytobenthos) in the lagoon system.

\section{Materials and Methods}

\section{Study area}

The study area, Hichirippu Lagoon, is located on the coast facing the Pacific Ocean in the eastern part of Hokkaido, Japan $\left(43^{\circ} 03^{\prime} \mathrm{N}, 145^{\circ} 00^{\prime} \mathrm{E}\right.$, Fig. 1). The lagoon covers an area of $3.58 \mathrm{~km}^{2}$ and its water depth is extremely shallow (mean water depth of ca. $1 \mathrm{~m}$ ). The tidal flats, which are shown in Fig. 1 at a low water level $(<50 \mathrm{~cm})$, cover an area of ca. $0.19 \mathrm{~km}^{2}$ (Komorita et al. 2010). The sediment is muddy sand with a mud content of less than $28.1 \%$ throughout the entire lagoon (Kajihara et al. 2010). In winter (November to March), the innermost part of the lagoon is covered by ice. We established four sampling stations in the subtidal zones of the lagoon (Stns A-C, Stn TL, Fig. 1).

\section{Field sampling}

We conducted a 36-h continuous survey from August 21 to 23 , in 2003, at Stn B. Water samples were collected every $3 \mathrm{~h}$ from the surface and from $10 \mathrm{~cm}$ above the sea floor (bottom), and kept in $2 \mathrm{~L}$ plastic bottles. The bottom water was collected using a motor pump (YPM-12, flow rate: $70 \mathrm{~L} \mathrm{~min}^{-1}$, intake diameter: $105 \mathrm{~mm}$, Meiwa). We did not collect water samples at 21:00 on August 22 due to low visibility. Sinking particle samples were taken at 12 -h intervals using a sediment trap system (Table 1, Fig. 2), which

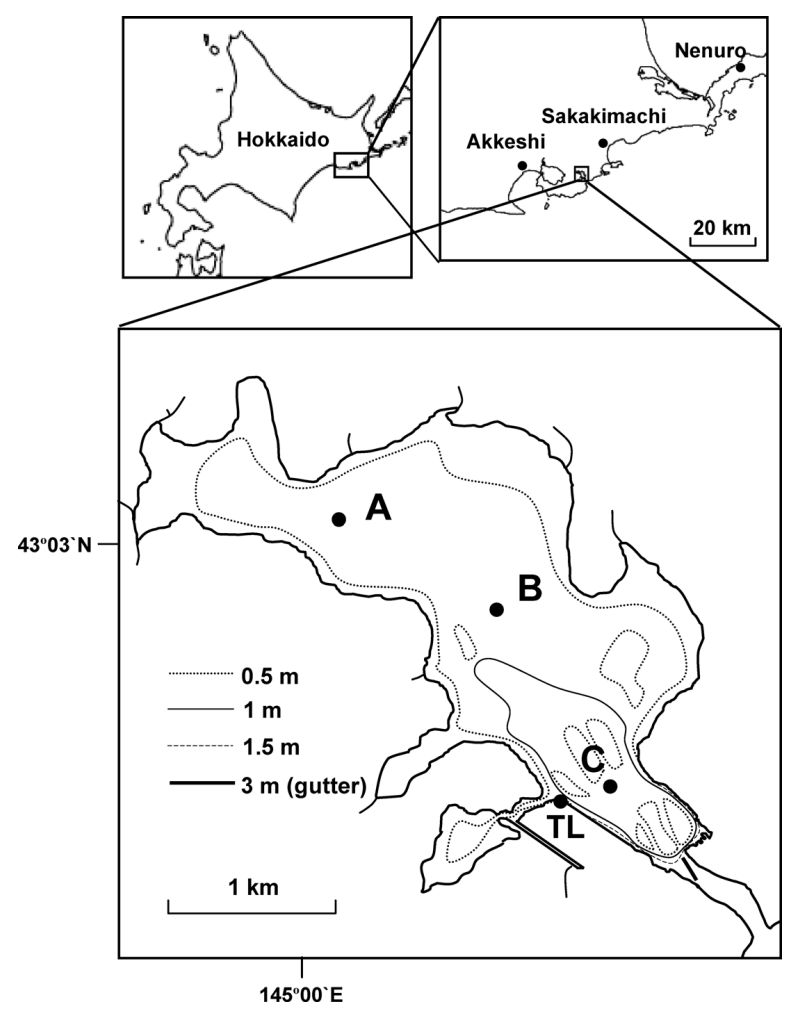

Fig. 1. Location map of sampling stations in Hichirippu Lagoon. 
Table 1. Sampling regime.

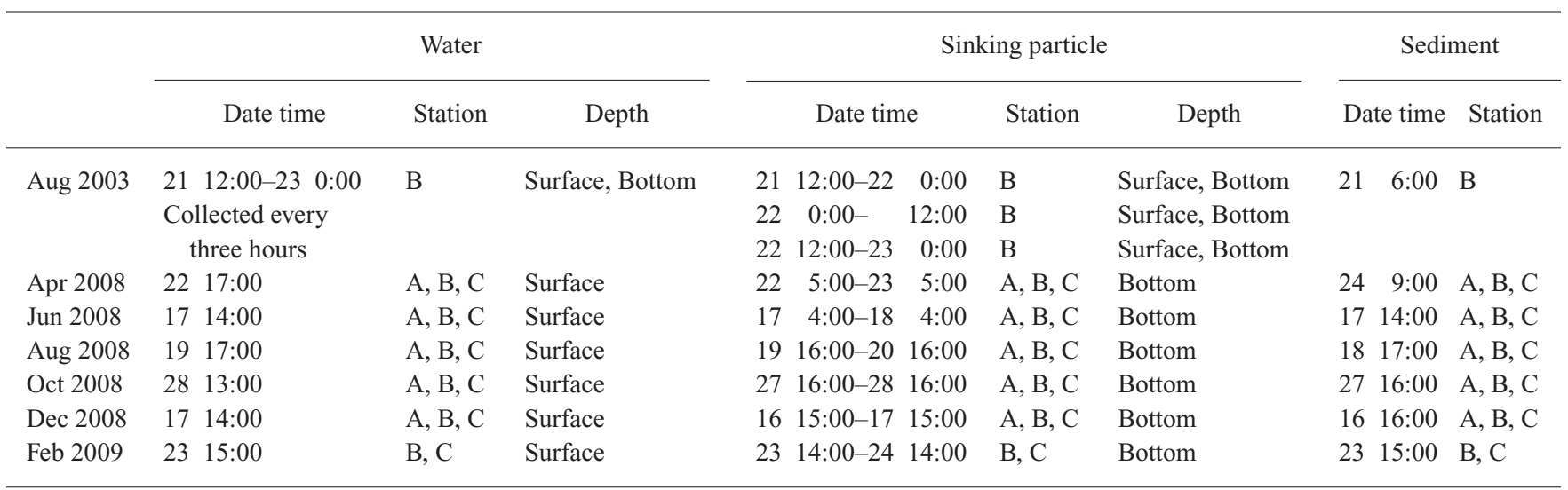

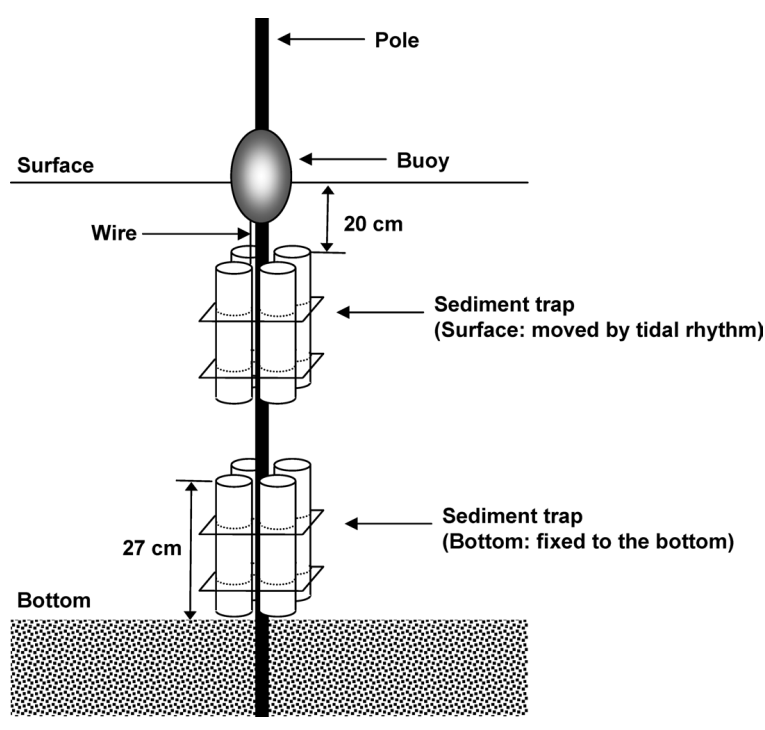

Fig. 2. Illustration of sediment trap system.

consisted of acrylic resin frames and two sets of four transparent acrylic resin cylinders, each $27 \mathrm{~cm}$ high and $8.3 \mathrm{~cm}$ across. Using a floating buoy, the sediment trap system for the surface layer shifted with the tidal rhythm, and the traps were kept in a position $20 \mathrm{~cm}$ below the water surface (Fig. 2). The cylinder trap contains a $5 \mathrm{~cm}$ deep $\times 1 \mathrm{~cm} \times 1 \mathrm{~cm}$ grid at the bottom. During this period, the tide level was monitored using a tide indicator fixed on a picket in the ground (RMD-5225A, Rigo Co. Ltd.) every 10 minutes at Stn TL (Fig. 1). At 6:00 on 21 August 2003, we carried out the sampling of sediment at Stn B (Table 1). A grab sample of the sediment was collected with an Ekman-Berge grab sampler $(20 \mathrm{~cm} \times 20 \mathrm{~cm}$, Rigo Co. Ltd.). Ten core samples of the sediment were subsampled from a grab sample using an acrylic core tube ( $3 \mathrm{~cm}$ in diameter). The surface layers of the sediment up to a depth of $5 \mathrm{~mm}$ were sliced from the core samples and kept in a plastic bag. Since these samplings took place over the course of cruises that lasted $1-2 \mathrm{~h}$, the samples were stored on the boat in a cooler box.

From April 2008 to February 2009, we conducted bi- monthly samplings of water, sinking particles, and sediment at Stns A, B and C (Table 1). These samples were collected in the same way as was done in August 2003. Water samples from the bottom were not collected during this period. The sinking particle samples for the bottom layer were collected for $24 \mathrm{~h}$ of each month (Table 1). In February 2009, samples were not collected at Stn A, which was covered with ice.

\section{Analytical methods}

The water samples collected in August 2003 were used for chlorophyll $a$ (Chl-a), suspended particle weight, and particulate organic carbon (POC) analysis. For the determination of the Chl- $a$ concentration of the water, $0.4 \mathrm{~L}$ of the water sample was filtered with a glass fiber filter $(\mathrm{GF} / \mathrm{F}$, Whatman). Chl- $a$ on the filter was extracted in $7 \mathrm{~mL}$ of 90\% acetone in a test tube and kept in a freezer (dark conditions at $-20^{\circ} \mathrm{C}$ ) for a day. After ultrasonication treatment for five minutes, the concentrations of Chl- $a\left(\mu \mathrm{g} \mathrm{L}^{-1}\right)$ in the supernatants of the test tube were determined with a fluorophotometer (10-AU-5, Turner Designs) according to Lorenzen's (1967) method as described by Parsons et al. (1984). Measurements of the Chl- $a$ concentration in the surface water were also expressed in terms of standing stock (mg Chl- $a \mathrm{~m}^{-2}$ ) in the water column by multiplying the volume of the water column by the water depth $(1 \mathrm{~m})$. The Chl- $a$ content of the suspended particles ( $\mu \mathrm{g}$ Chl- $a \mathrm{~g}^{-1}$ ) was also obtained by dividing the Chl- $a$ concentration by the suspended particle concentration. For the determination of the suspended particle weight and POC concentration of the water samples, $0.5 \mathrm{~L}$ of the water sample was filtered with a precombusted $\mathrm{GF} / \mathrm{F}$ filter $\left(450^{\circ} \mathrm{C}, 5 \mathrm{~h}\right)$, and the dry weight of the filter was determined after drying at $60^{\circ} \mathrm{C}$ for 24 hours. Suspended particle concentration $\left(\mathrm{mg} \mathrm{L}^{-1}\right)$ was obtained on the basis of the increase in the dry weight of the filter before and after filtration. The POC content on the filter was determined by high temperature oxidation using a CHN analyzer (Carbon, Hydrogen, and Nitrogen analyzer, MT-3, Yanaco) after carbonates had been removed with hy- 
drochloric acid. The carbon content of the water samples ( $\mathrm{m} \mathrm{C}^{-1}$ ) was also obtained by dividing the POC content by the weight of the suspended particles on the filter. The water samples collected during April 2008 and February 2009 were used for Chl- $a$ analysis in the same way as the samples collected in August 2003.

The sinking particle samples collected in August 2003 were used for Chl- $a$, sinking particle weight, POC, and stable isotope analysis. Prior to the filtration, the cylinder trap was kept stationary for $1 \mathrm{~h}$ and the supernatant was carefully discarded using a silicone tube. The residues of 3 cylinders were filtered with pre-combusted $\left(450^{\circ} \mathrm{C}, 5 \mathrm{~h}\right)$ $\mathrm{GF} / \mathrm{F}$ filters. To determine the Chl- $a$ content of the sinking particles, Chl- $a$ on the filter was extracted in $7 \mathrm{~mL}$ of $90 \%$ acetone in a test tube. The concentrations of Chl- $a\left(\mu \mathrm{g} \mathrm{L}^{-1}\right)$ were analyzed in the same way as in the water samples. The total Chl- $a$ of the sinking particles ( $\mu$ g Chl- $a$ ) was determined by multiplying the Chl- $a$ concentration by the acetone volume. To determine the sinking particle weight and POC and to perform stable isotope analysis, two other filters were immediately dried at $60^{\circ} \mathrm{C}$ for $24 \mathrm{~h}$. The sinking particle weight (mg) was obtained on the basis of the increase in the dry weight of the filter before and after filtration. POC content $\left(\mathrm{mg} \mathrm{C} \mathrm{g}^{-1}\right)$ was analyzed in the same way as in the water sample. The Chl- $a$ content of the sinking particles ( $\mu \mathrm{g} \mathrm{Chl}-a \mathrm{~g}^{-1}$ ) was also obtained by dividing the total Chl- $a$ by the sinking particle weight. We calculated the sinking particle flux $\left(\mu \mathrm{g} \mathrm{m}^{-2} \mathrm{~h}^{-1}, \mathrm{mg} \mathrm{m}^{-2}\right.$ day $^{-1}$ ) using the following equation.

$$
\begin{gathered}
\text { Mass flux }=\text { sinking particle weight } / \mathrm{D} / \mathrm{T} \\
\text { Chl }-a \text { flux }=\text { Mass flux } \times \text { Chl }-a \text { content }
\end{gathered}
$$

where $\mathrm{D}=$ the dimensions of the cylinder trap $\left(\mathrm{m}^{2}\right)$, and $\mathrm{T}=$ the installation time of the sediment trap ( $h$, day). For sinking particles on the filter, isotopic analyses were carried out by Shoko Co., Ltd., using an isotope-ratio mass spectrometer, (EA1110-DELTA Plus Advantage ConFlo III System). The analysis was expressed according to conventional standards, namely Pee Dee Belemnite for carbon expressed in terms of \%ovalues, defined as $\delta \mathrm{X}=(\mathrm{R}$ sample $-\mathrm{R}$ standard $) / R$ standard $\times 10^{3}(\%)$, where $\mathrm{X}={ }^{13} \mathrm{C}$, and $\mathrm{R}={ }^{13} \mathrm{C} /{ }^{12} \mathrm{C}$. The experimental precision was better than $0.15 \%$. The sinking particle samples collected during April 2008 and February 2009 were used for Chl- $a$ and sinking particle weight analysis in the same way as the samples collected in August 2003.

The sediment samples collected in August 2003 were used for Chl- $a$, organic carbon content, and stable isotope analysis. To determine the Chl- $a$ content of the sediment, about $0.3 \mathrm{~g}$ of the sediment sample was put in a test tube with $90 \%$ acetone, and the test tube was kept in the freezer for a day. The supernatant of the test tube was treated in the same manner as the Chl- $a$ extract from the water sample. The Chl- $a$ content in the sediment ( $\mu \mathrm{g}$ Chl- $a \mathrm{~g}^{-1}$ ) was also expressed over the area (mg Chl- $a \mathrm{~m}^{-2}$, a depth of 0 to $5 \mathrm{~mm}$ ) by taking the spatial and temporal variations of the porewater content into consideration (for details, see Montani et al. 2003). The water content of the sediment sample was obtained after drying at $60^{\circ} \mathrm{C}$ for $24 \mathrm{~h}$. The Chl- $a$ standing stock of the sediment was calculated from the data for the amount of Chl- $a$ extracted from the sediment sample and the water content. For the organic carbon and stable isotope analysis, sediment samples were freeze-dried and ground into a powder with a mortar. Prior to the analysis,

\begin{tabular}{|c|c|c|c|c|c|c|c|c|}
\hline & $\begin{array}{r}\text { Date time } \\
\text { August } 200\end{array}$ & & Depth $^{\mathrm{a}}$ & $\begin{array}{c}\text { Chl- } a \\
\left(\mu \mathrm{gg}^{-1}\right)\end{array}$ & $\begin{array}{c}\text { Carbon } \\
\left(\mathrm{mg} \mathrm{g}^{-1}\right)\end{array}$ & $\begin{array}{c}\delta^{13} \mathrm{C}-\mathrm{PDB} \\
(\%)\end{array}$ & & References \\
\hline \multirow[t]{7}{*}{ Water } & $21 \quad 12: 00-22$ & $0: 00$ & Surface & $96.1 \pm 71.3$ & $34.0 \pm 18.8$ & n.d. & $\mathrm{n}=4$ & This study \\
\hline & & & Bottom & $120 \pm 122$ & $28.8 \pm 11.7$ & n.d. & $\mathrm{n}=4$ & \\
\hline & $22 \quad 0: 00-$ & $12: 00$ & Surface & $105 \pm 94.1$ & $38.2 \pm 23.1$ & n.d. & $n=4$ & \\
\hline & & & Bottom & $55.5 \pm 44.1$ & $22.9 \pm 20.3$ & n.d. & $n=4$ & \\
\hline & $2212: 00-23$ & 0:00 & Surface & $60.5 \pm \quad 5.5$ & $35.8 \pm 6.8$ & n.d. & $\mathrm{n}=4$ & \\
\hline & & & Bottom & $83.6 \pm 88.8$ & $32.3 \pm 2.3$ & n.d. & $\mathrm{n}=4$ & \\
\hline & Average & & & $86.8 \pm 74.7^{*}$ & $32.0 \pm 14.8^{\text {n.s. }}$ & n.d. & $\mathrm{n}=24$ & \\
\hline \multirow[t]{7}{*}{ Sinking particle } & $21 \quad 12: 00-22$ & 0:00 & Surface & 24.6 & 19.3 & -18.7 & & This study \\
\hline & & & Bottom & 8.4 & 10.6 & -15.9 & & \\
\hline & $22 \quad 0: 00-$ & $12: 00$ & Surface & 73.3 & 33.4 & -18.2 & & \\
\hline & & & Bottom & 42.1 & 18.0 & -17.8 & & \\
\hline & $2212: 00-23$ & 0:00 & Surface & 31.0 & 28.7 & -17.4 & & \\
\hline & & & Bottom & 20.8 & 18.1 & -15.9 & & \\
\hline & Average & & & $35.9 \pm 22.5^{*}$ & $21.4 \pm 8.2^{\text {n.s. }}$ & $-17.6 \pm 1.2$ & $\mathrm{n}=6$ & \\
\hline Sediment & $216: 00$ & & & 32.4 & 13.8 & -17.8 & & This study \\
\hline \multicolumn{4}{|c|}{ Particulate organic matter } & & & $-19.2 \pm 1.0$ & & Kajihara et al. (2010) \\
\hline \multicolumn{4}{|c|}{ Microphytobenthos } & & & $-16.0 \pm 1.6$ & & Kajihara et al. (2010) \\
\hline \multicolumn{4}{|c|}{ Phytoplankton } & & & -22.2 to -20.3 & & Gearing et al. (1984) \\
\hline
\end{tabular}

Table 2. The chemical composition of water, sinking particle and sediment samples. The $p$ value is based on Student's t-test.

\footnotetext{
${ }^{\text {a }}$ Sampling layer: see text for more details.
} 
the samples were treated with $1 \mathrm{~N} \mathrm{HCl}$ to remove inorganic carbon, rinsed with deionized and distilled water to remove the acid, and freeze-dried. For the analysis of organic carbon $\left(\mathrm{mg} \mathrm{C} \mathrm{g}^{-1}\right)$, sediment samples were analyzed with a $\mathrm{CN}$ elemental analyzer (NA-1500, Faisons). Isotopic analyses were also carried out by Shoko Co., Ltd., in the same manner as used for the sinking particle samples. The sediment samples collected during April 2008 and February 2009 were used for Chl- $a$ analysis in the same way as the samples collected in August 2003.

\section{Data analysis}

Applying the two-source linear mixing model with $\delta^{13} \mathrm{C}$, the mass balance for the carbon isotope is,

$$
\begin{gathered}
\delta^{13} \mathrm{C}_{\mathrm{M}}=\mathrm{R}_{\mathrm{X}} \delta^{13} \mathrm{C}_{\mathrm{X}}+\mathrm{R}_{\mathrm{Y}} \delta^{13} \mathrm{C}_{\mathrm{Y}} \\
1=\mathrm{R}_{\mathrm{X}}+\mathrm{R}_{\mathrm{Y}}
\end{gathered}
$$

where $\delta^{13} \mathrm{C}_{\mathrm{M}}, \delta^{13} \mathrm{C}_{\mathrm{X}}$, and $\delta^{13} \mathrm{C}_{\mathrm{Y}}$ represent the $\delta^{13} \mathrm{C}$ values for $\mathrm{M}, \mathrm{X}$ and $\mathrm{Y}$, respectively. The subscripts $\mathrm{X}, \mathrm{Y}$ and $\mathrm{M}$ represent two sources and a mixture, respectively. $\mathrm{R}_{\mathrm{X}, \mathrm{Y}}$ represents the fractional contribution rate of $\delta^{13} \mathrm{C}$ from each source to the mixture. Using the mixing model, the rates of contribution of microphytobenthos $\left(\mathrm{R}_{\mathrm{MPB}}\right)$ and phytoplankton $\left(\mathrm{R}_{\mathrm{PHY}}\right)$ to the mixture (i.e. sinking particles or particulate organic matter) were calculated from the following equations.

$$
\begin{aligned}
& \mathrm{R}_{\mathrm{MPB}}(\%)=\left(\delta^{13} \mathrm{C}_{\mathrm{PHY}}-\delta^{13} \mathrm{C}_{\mathrm{M}}\right) /\left(\delta^{13} \mathrm{C}_{\mathrm{PHY}}-\delta^{13} \mathrm{C}_{\mathrm{MPB}}\right) \\
& \mathrm{R}_{\mathrm{PHY}}(\%)=\left(\delta^{13} \mathrm{C}_{\mathrm{MPB}}-\delta^{13} \mathrm{C}_{\mathrm{M}}\right) /\left(\delta^{13} \mathrm{C}_{\mathrm{MPB}}-\delta^{13} \mathrm{C}_{\mathrm{PHY}}\right)
\end{aligned}
$$

where $\delta^{13} \mathrm{C}_{\mathrm{M}}, \delta^{13} \mathrm{C}_{\mathrm{MPB}}$ and $\delta^{13} \mathrm{C}_{\mathrm{PHY}}$ are the $\delta^{13} \mathrm{C}$ values for the mixture, microphytobenthos, and phytoplankton, respectively. The end-member compositions, $\delta^{13} \mathrm{C}_{\mathrm{PHY}}$ and $\delta^{13} \mathrm{C}_{\mathrm{MPB}}$, that were used were -22.2 to $-20.3 \%$, and $-16.0 \%$, respectively. $\delta^{13} \mathrm{C}_{\mathrm{PHY}}$ was reported in Narragansett Bay $\left(41^{\circ} 35^{\prime} \mathrm{N}\right)$ by Gearing $(1984)$, and $\delta^{13} \mathrm{C}_{\mathrm{MPB}}$ was examined in the same area in Hichirippu Lagoon by Kajihara et al. (2010) (Table 2).

\section{Results}

\section{Thirty-six-hour continuous survey}

The temporal variations in tide level and in Chl- $a$, suspended particle, and POC concentrations, August 21-23, 2003, are shown in Fig. 3. During this period, there were two high tides and one low tide. The tide level reached the lowest low tide at $6: 00$ on August $22(58.5 \mathrm{~cm})$. The concentration of Chl- $a$ in the surface water ranged from 0.3 to $2.5 \mu \mathrm{g} \mathrm{L}^{-1}(0.9 \pm 0.6 \mu \mathrm{g} \mathrm{L}-1$, mean $\pm \mathrm{SD})$ and that in the bottom water ranged from 0.4 to $7.4 \mu \mathrm{g} \mathrm{L}^{-1}\left(2.4 \pm 2.1 \mu \mathrm{g} \mathrm{L}^{-1}\right)$. The Chl- $a$ concentrations of the bottom water tended to be higher than those of the surface water. In both the bottom and surface water, the Chl- $a$ concentration peaked at 3:00 on August 22 before the lowest low tide. The temporal vari-
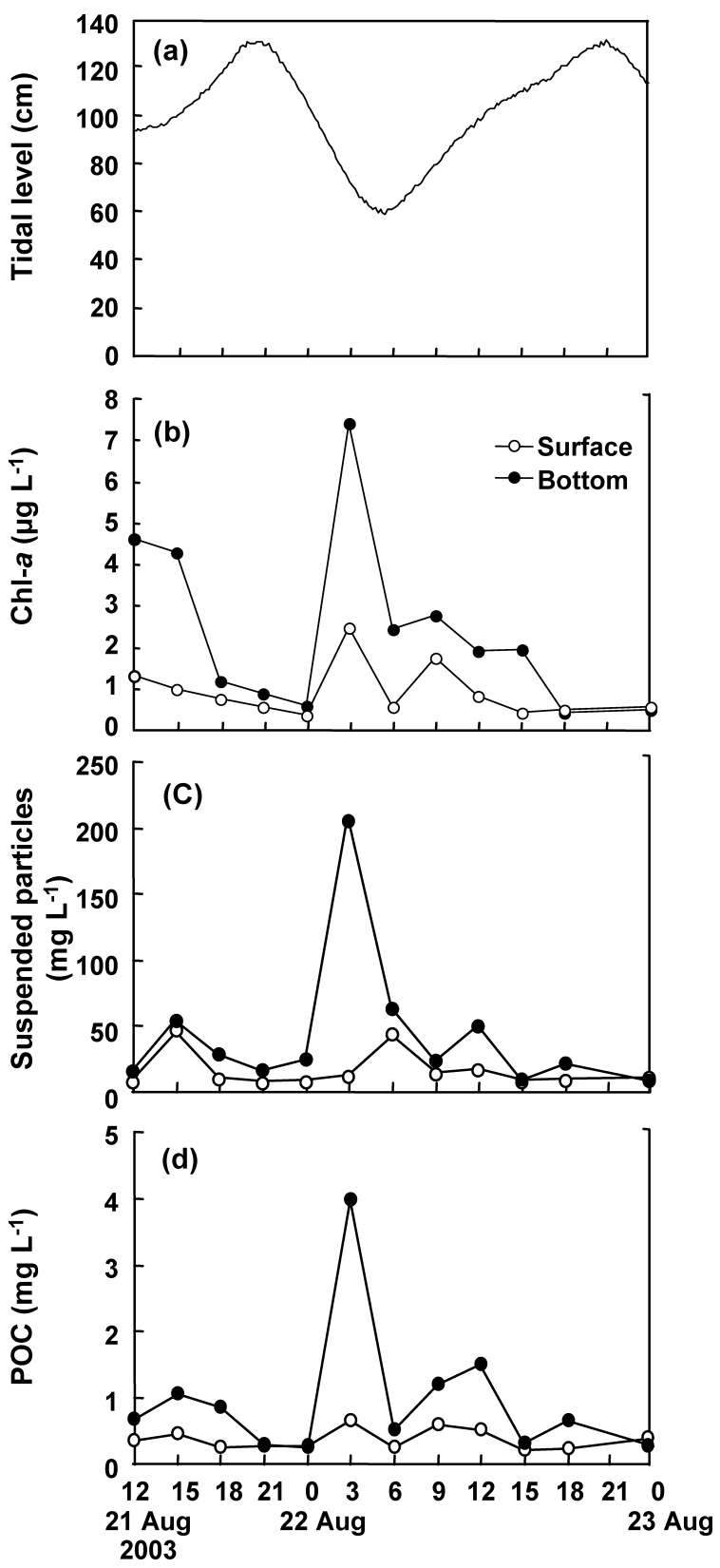

Fig. 3. Variations in (a) tide level (cm) at Stn TL, (b) Chl- $a$ concentration $\left(\mu \mathrm{g} \mathrm{L}^{-1}\right)$, (c) suspended particle concentration $\left(\mathrm{mg} \mathrm{L}^{-1}\right)$, and (d) particulate organic carbon concentration $\left(\mathrm{mg} \mathrm{L}^{-1}\right)$ in surface and bottom waters observed every $3 \mathrm{~h}$ at Stn B during a 36-h period on August 21-23, 2003.

ations of the suspended particle and POC concentrations occurred in parallel with those of Chl- $a$, and the concentrations peaked at $205 \mathrm{mg} \mathrm{L}^{-1}$ and $4.0 \mathrm{mg} \mathrm{L}^{-1}$ at 3:00 on August 22, respectively. The suspended particle and POC concentrations of the bottom water tended to be higher than those of the surface water. The averaged Chl- $a$ content and carbon content of the suspended particles in the water column ranged between 55.5 and $120 \mu \mathrm{gg}^{-1}(86.8 \pm 74.7$ $\mu \mathrm{gL}^{-1}$, mean $\left.\pm \mathrm{SD}\right)$ and between 22.9 and $38.2 \mathrm{mg} \mathrm{g}^{-1}$ $\left(32.0 \pm 14.8 \mathrm{mg} \mathrm{g}^{-1}\right)$, respectively (Table 2 ). 
The fluxes of Chl- $a$ in the surface and bottom layers are shown in Fig. 4. During the low tide period (0:00-12:00 on August 22), the Chl- $a$ fluxes of the surface and bottom layers reached their highest values. The fluxes of the bottom layer were higher than those of the surface layer. The averaged content of Chl- $a$ of the sinking particles was significantly lower than that of the suspended particles in the water column (Student's t-test $p<0.01$, Table 2). In contrast, the averaged carbon content of the sinking particles

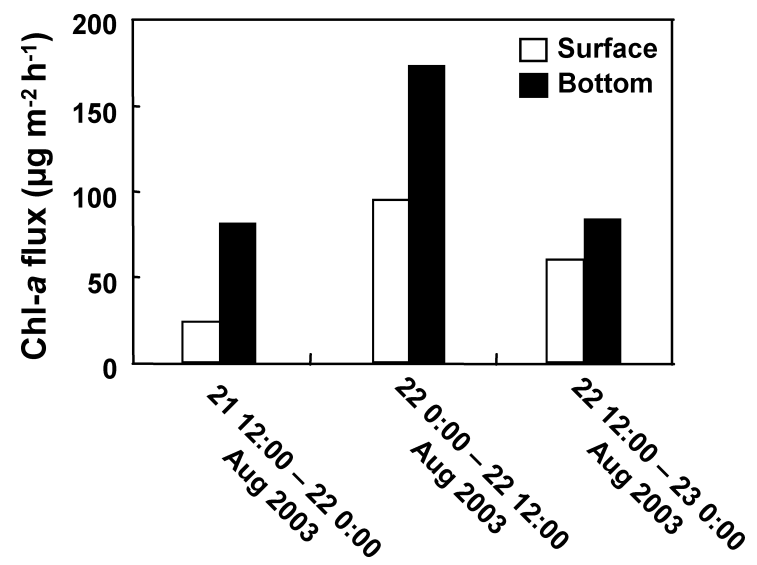

Fig. 4. The flux of Chl- $a\left(\mu \mathrm{g} \mathrm{m}^{-2} \mathrm{~h}^{-1}\right)$ collected in 2003 during the following periods: 21 August 12:00-22 August 0:00; $22 \mathrm{Au}-$ gust 0:00-12:00; and 22 August 12:00-23 August 0:00 at Stn B. showed no significant difference from that of the suspended particles in the water column (Table 2). The $\delta^{13} \mathrm{C}$ values of the sinking particles in the surface and bottom layers collected at $12-\mathrm{h}$ intervals ranged from -18.7 to $-15.9 \%$ $(-17.3 \pm 1.2 \%$, mean $\pm \mathrm{SD}, \mathrm{n}=6$, Table 2$)$. Using the mean $\delta^{13} \mathrm{C}$ value of the sinking particles $\left(\delta^{13} \mathrm{C}_{\text {Sink }}\right)$, i.e., $-17.3 \%$, the rates of contribution of microphytobenthos $\left(\mathrm{R}_{\mathrm{MPB}}\right)$ and phytoplankton $\left(\mathrm{R}_{\mathrm{PHY}}\right)$ to the sinking particles were 63 to $74 \%$ and 26 to $37 \%$, respectively.

The chemical composition of the sediment on 21 August 2003 is shown in Table 2. The contents of Chl- $a$ and carbon in the sediment were $32.4 \mu \mathrm{g} \mathrm{g}^{-1}$ and $13.8 \mathrm{mg} \mathrm{g}^{-1}$, respectively. They are in the same range as those in the sinking particles. The value of $\delta^{13} \mathrm{C}$ of the sediment was $-17.8 \%$, which was in the same range as that in the sinking particles (Table 2).

\section{Chlorophyll $\boldsymbol{a}$ fluxes and standing stocks of Chlorophyll $a$ in the water column and surface sediment}

Table 3 shows the spatial and temporal variations in the Chl- $a$ fluxes of the sinking particles and of the standing stock of Chl- $a$ in the water column and surface sediment in the uppermost $5 \mathrm{~mm}$ at Stns A-C. The fluxes of Chl- $a$ measured by the trap ranged from 0.7 (Stn B, August) to 10.3 (Stn A, April) $\mathrm{mg} \mathrm{m}^{-2} \mathrm{day}^{-1}$. The standing stock of Chl- $a$ in the water column ranged from 0.4 to $9.3 \mathrm{mg} \mathrm{m}^{-2}$ and

Table 3. Temporal and spatial variations in the Chl- $a$ fluxes of sinking particles, the standing stock of Chl- $a$ in the water column, the standing stock of Chl- $a$ in the surface sediment at a depth of 0 to $5 \mathrm{~mm}$, and the relative percentages at Stn A, B, and C from April 2008 to February 2009.

\begin{tabular}{|c|c|c|c|c|c|c|c|}
\hline & & \multirow{2}{*}{ Station } & \multirow{2}{*}{$\begin{array}{c}\text { Chl- } a \text { flux } \\
\left(\mathrm{mg} \mathrm{m}^{-2} \mathrm{day}^{-1}\right)\end{array}$} & \multicolumn{2}{|c|}{ Chl- $a$ standing stock ( $\mathrm{mg} \mathrm{m}^{-2}$ ) } & \multicolumn{2}{|c|}{ Relative percentage (\%) } \\
\hline & & & & Water & Sediment & Water $^{\mathrm{a}}$ & Sediment ${ }^{\mathrm{b}}$ \\
\hline \multirow{3}{*}{\multicolumn{2}{|c|}{2008 April }} & Stn A & 10.3 & 1.6 & 96.2 & 663 & 10.7 \\
\hline & & Stn B & 5.3 & 2.9 & 75.0 & 187 & 7.1 \\
\hline & & Stn C & 6.6 & 3.5 & 139 & 189 & 4.7 \\
\hline \multirow{3}{*}{\multicolumn{2}{|c|}{ June }} & Stn A & 10.0 & 9.3 & 83.6 & 107 & 11.9 \\
\hline & & Stn B & 1.6 & 3.4 & 102 & 47.0 & 1.6 \\
\hline & & Stn $\mathrm{C}$ & 10.0 & 2.3 & 35.9 & 430 & 27.8 \\
\hline \multirow{3}{*}{\multicolumn{2}{|c|}{ August }} & Stn A & 5.5 & 0.6 & 51.7 & 905 & 10.7 \\
\hline & & Stn B & 0.7 & 0.7 & 80.0 & 102 & 0.9 \\
\hline & & Stn $\mathrm{C}$ & 6.7 & 1.8 & 110 & 372 & 6.1 \\
\hline \multirow{3}{*}{\multicolumn{2}{|c|}{ October }} & Stn A & 4.1 & 0.6 & 111 & 630 & 3.7 \\
\hline & & Stn B & 2.2 & 0.7 & 184 & 329 & 1.2 \\
\hline & & Stn C & 2.9 & 0.8 & 87.3 & 386 & 3.3 \\
\hline & December & Stn A & 4.8 & 5.0 & 75.2 & 96.9 & 6.4 \\
\hline & & Stn B & 3.1 & 0.5 & 150 & 666 & 2.1 \\
\hline & & Stn C & 5.1 & 0.4 & 131 & 1270 & 3.9 \\
\hline \multirow[t]{4}{*}{2009} & February & Stn A & n.d. & n.d. & n.d. & n.d. & n.d. \\
\hline & & Stn B & 4.3 & 1.5 & 182 & 286 & 2.4 \\
\hline & & Stn C & 8.5 & 1.7 & 131 & 487 & 6.5 \\
\hline & Average & & 5.4 & 2.2 & 107 & 421 & 6.5 \\
\hline
\end{tabular}

${ }^{\text {a }}$ Calculated by dividing the Chl- $a$ flux by the Chl- $a$ standing stock in the water column.

${ }^{\mathrm{b}}$ Calculated by dividing the Chl- $a$ flux by the Chl- $a$ standing stock in the sediment. 
showed higher values at Stn A (June and December 2008), though the spatial and temporal variation in the values in the water column showed no clear trends either along the transect line or in terms of seasonal change (Table 3). The daily Chl- $a$ fluxes accounted for $47.0 \%$ (Stn B, June) to $1,270 \%$ (Stn C, December) of the total standing stock of Chl- $a$ in the water column in the same area, and they were higher than the total Chl- $a$ in the water column in 15 of the 17 cases (relative percentage $>100 \%$, Table 3 ). The standing stock of Chl- $a$ in the surface sediment was highest, $184 \mathrm{mg} \mathrm{m}^{-2}$, at Stn B in October, and lowest, $35.9 \mathrm{mg} \mathrm{m}^{-2}$, at Stn C in June. The standing stock of Chl- $a$ in the surface sediment was 9.0 (Stn A, June) to 325 (Stn B, December) times larger than that in the water column in the same area. The relative percentage of daily Chl- $a$ flux divided by the standing stock of Chl- $a$ in the surface sediment $(5 \mathrm{~mm})$ ranged from 0.9 to $27.8 \%$ with a mean value of $6.5 \%$ $(n=17)$.

\section{Discussion}

\section{Source of Chlorophyll $a$ collected in sediment traps}

Resuspension occurs as a result of tidal currents and wave action (Baillie \& Welsh 1980, Lucas et al. 2000). Although the waves in shallow water may not be very large, in general they can still cause considerable resuspension. The Hichirippu Lagoon system is dominated by a tidal current, and its water depth is extremely shallow (mean water depth of ca. $1 \mathrm{~m}$, Suga et al. 2011). In this lagoon, resuspension seemed to have an effect on suspended particulate matter in the surface water. Using microscopic examination, Lucas (2003) observed resuspended benthic diatoms at the turbid edge of the water, particularly in the trailing edge of the ebb tide. In our study area, the high Chl- $a$ flux measured in the samples collected in the sediment traps came from the turbid edge (low tide period) (Fig. 4). Although the physical characteristics of Hichirippu Lagoon are well mixed vertically (Suga et al. 2011), the Chl- $a$, suspended particle, and POC concentrations of the bottom water were higher than those of the surface water, and they peaked at the trailing edge of the ebb tide at 3:00 on August 22 (Fig. 3). The Chl$a$ fluxes of the bottom layer were higher than those of the surface layer. As previous studies have also reported (Shaffer \& Sullivan 1988), in our study area it can be seen that much of the spatial variability in the Chl- $a$ concentration of the water column was the result of resuspended microphytobenthos. In addition, the standing stock of Chl- $a$ in the surface sediment was 9.0 to 325 times larger than that of the water column in the same area (Table 3). This large amount of standing stock indicates that microphytobenthos luxuriated widely on the sediment surface of the lagoon and that the microphytobenthic biomass is much higher than the phytoplankton biomass. The daily Chl- $a$ fluxes contributed from $47.0 \%$ to $1,270 \%$ of the total standing stock of Chl- $a$ in the water column in the same area (Table 3), and they were higher than those of the water column Chl- $a$ in 15 of the 17 cases (Table 3). In other words, the standing stock of Chl- $a$ in the water column was not sufficient to support the daily sinking Chl- $a$ flux.

These results would imply that the Chl- $a$ collected in sediment traps consisted of resuspended microphytobenthos. To test this hypothesis, we focused on the source of the Chl- $a$ in the sinking particles. The rates of contribution of microphytobenthos $\left(\mathrm{R}_{\mathrm{MPB}}\right)$ and phytoplankton $\left(\mathrm{R}_{\mathrm{PHY}}\right)$ in sinking particles were 63 to $74 \%$ and 26 to $37 \%$, respectively, which would imply that the contribution of microphytobenthic resuspension to the Chl- $a$ collected in the traps is much higher than that of phytoplankton. Gabrielson \& Lukatelich (1985) reported that the resuspension of bottom sediments accounted for 69 to $92 \%$ of the total sinking fluxes, on the basis of organic matter content measured at 5 sites in the Peel-Harvey Estuarine System, Western Australia. The rate of contribution of microphytobenthos in this study is within the range reported by Gabrielson \& Lukatelich (1985). The $\delta^{13} \mathrm{C}$ value of particulate organic matter $\left(\delta^{13} \mathrm{C}_{\mathrm{POM}}\right)$ collected in the same area, Hichirippu Lagoon, was $-19.2 \pm 1.0 \%$ o (mean $\pm \mathrm{SD}$ ) (Kajihara et al. 2010, Table 2). The $\delta^{13} \mathrm{C}_{\mathrm{POM}}$ in Hichirippu Lagoon was higher than the $\delta^{13} \mathrm{C}_{\mathrm{PHY}}$ values reported by France (1995) and Gearing (1984), which suggests that the particulate organic matter in the water column did not consist only of phytoplankton. Using the $\delta^{13} \mathrm{C}_{\mathrm{POM}}$, the $\mathrm{R}_{\mathrm{MPB}}$ and $\mathrm{R}_{\mathrm{PHY}}$ in particulate organic matter were also calculated by the mixing model. The $\mathrm{R}_{\mathrm{MPB}}$ and $\mathrm{R}_{\mathrm{PHY}}$ in particulate organic matter were 26 to $48 \%$ and 52 to $74 \%$, respectively. The rates suggest that microphytobenthos account for up to $48 \%$ of the particulate organic matter in the water column, which is consistent with our result that the spatial variability in the Chl- $a$ concentration of the water column was caused by resuspended microphytobenthos.

The averaged carbon content in the sinking particles was not significantly different from those in the water and sediment samples. This finding suggests that the source of carbon is the same in the suspended particles of the water column, the sinking particles, and the sediment. As Floderus (1989) pointed out, since the sinking particles have the same chemical composition of carbon as the suspended particles in the water column, we could not estimate the resuspended particle flux based on carbon. The averaged Chl- $a$ content in the sinking particles was significantly lower than that in the water column, and the Chl- $a$ content in the sediment was in the same range as that in the sinking particles. Therefore, the source of Chl- $a$ in sinking particles seemed not to be phytoplankton in the water column but rather microphytobenthos. This hypothesis is supported by the similarity of $\delta^{13} \mathrm{C}$ between sinking particles and sediment (Table 2).

Our results thus confirm that the contribution of the phytoplankton present in the water column to the Chl- $a$ collected in the traps is likely to be negligible, and the origin of the Chl- $a$ collected in the sediment traps consisted 
mainly of microphytobenthos. Consequently, we assumed that all the Chl- $a$ fluxes in this study were microphytobenthic resuspension fluxes.

\section{Effect of microphytobenthic resuspension on pelagic and benthic microalgae}

De Jonge \& Van Beusekom (1992) estimated that the microphytobenthic resuspension contributed up to $60 \%$ of the total water column Chl- $a$ in the Ems estuary. In our study, the daily Chl- $a$ fluxes contributed $47.0-1,270 \%$ of the total water column Chl- $a$ (Table 3). This finding suggests that the resuspended microphytobenthos have a major impact on the total microalgal biomass in the water column.

The mean relative percentage of daily Chl- $a$ flux divided by the standing stock of Chl- $a$ in sediment was $6.5 \%$ $(n=17)$, which indicates that approximately $7 \%$ of the microphytobenthos that are present in the sediment are resuspended. It is well known that microphytobenthos are characterized by vertical migration behavior. Tidal flooding and winnowing action remove aberrant and senescent individuals that fail to migrate down into the sediment (Kingston \& Gough 2009). In this study, $7 \%$ of the total microphytobenthos were resuspended and removed. In other words, 93\% of the total succeeded at escaping from the winnowing action by vertical migration. The individuals that failed to migrate down into the sediment were only a small part of the total microphytobenthic biomass. Young (1971) reported that a maximum of $2 \%$ of the sediment remained as permanent deposits and $98 \%$ was resuspended. Nevertheless, our result showed that a low percentage of $7 \%$ of microphytobenthos were resuspended. In our study area, the Chl- $a$ fluxes were as high as that reported in Suo-Sound (water depth $3-10 \mathrm{~m}$ ) in the western part of the Seto Inland Sea (4.0 to $9.9 \mathrm{mg} \mathrm{m}^{-2} \mathrm{day}^{-1}$ that was not resuspended flux, Yamaguchi et al. 2003). The standing stocks of Chl- $a$ in the surface sediment were in the same range as reported for similar latitudes, $42^{\circ} 19^{\prime}$ to $45^{\circ} 25^{\prime} \mathrm{N}\left(<1\right.$ to $330 \mathrm{mg} \mathrm{m}^{-2}$, MacIntyre et al. 1996). These data suggest that our estimation was not an anomalous value. Baillie \& Welsh (1980) commented that if 10 to $15 \%$ of the mudflat sediments were resuspended to a depth of $1 \mathrm{~mm}$, this could account for the Chl- $a$ levels in the water column inside the estuary. We therefore conclude that our estimate that approximately $7 \%$ of the microphytobenthos were resuspended has empirical support.

In our study, although the microphytobenthos biomass that failed to migrate down made up only $7 \%$ of the total, the daily Chl- $a$ fluxes contributed up to $1,270 \%$ of the total water column Chl- $a$. Consequently, in estuarine systems, although the resuspension phenomenon has little effect on the population of microphytobenthos, the resuspended microphytobenthos have a major impact on the total microalgal biomass in the water column.

\section{Acknowledgements}

Sampling was conducted with the much-appreciated cooperation of Mr. S. Nagasaka and the Chirippu Fishery Cooperative Union. We would also like to express our thanks to Dr. I. Kudo of Hokkaido University, Prof. Dr. H. Tsutsu$\mathrm{mi}$ and Dr. T. Komorita of the Prefectural University of Kumamoto, and Mr. N. Higaki of the Geological Survey of Hokkaido. In addition, we offer our thanks to the members of the Marine Environmental Science Laboratory of Hokkaido University, who helped with the field work.

\section{References}

Baillie PW, Welsh BL (1980) The effect of tidal resuspension on the distribution of intertidal epipelic algae in an estuary. Estuar Coast Mar Sci 10: 165-180.

Bloesch J (1994) A review of methods used to measure sediment resuspension Hydrobiologia 284: 13-18.

De Jonge VN, Van Beusekom JEE (1992) Contribution of resuspended microphytobenthos to total phytoplankton in the Ems estuary and its possible role for grazers. J Sea Res 30: 91-105.

Floderus S (1989) The effect of sediment resuspension on nitrogen cycling in the Kattegat - Variability in organic matter transport. UNGI Rapport Nr. 71, Thesis Uppsala University.

France RL (1995) Carbon-13 enrichment in benthic compared to planktonic algae: Foodweb implications. Mar Ecol Prog Ser 124: 307-312.

Gabrielson JO, Lukatelich RJ (1985) Wind-related resuspension of sediments in the Peel-Harvey Estuarine System. Estuar Coast Shelf Sci 20: 135-145.

Gasith A (1976) Seston dynamics and tripton sedimentation in the pelagic zone of a shallow eutrophic lake. Hydrobiologia 51: 225-231.

Gearing JN, Gearing PJ, Rudnick DT, Requuo AG, Hutchins MJ (1984) Isotopic variability of organic carbon in a phytoplankton-based, temperate estuary. Geochim Cosmochim Acta 48: 1089-1098.

Gruendling GK (1971) Ecology of the epipelie algal communities in Marion Lake, British Columbia. J Phycol 7: 239-249.

Kajihara R, Komorita T, Hamada A, Shibanuma S, Yamada T, Montani S (2010) Possibility of direct utilization of seagrass and algae as main food resources by small gastropod, Lacuna decorate, in a subarctic lagoon, Hichirippu, eastern Hokkaido, Japan with stable isotope evidences of carbon and nitrogen. Plankton Benthos Res 5: 90-97.

Kamermans P (1994) Similarity in food source and timing of feeding in deposit- and suspension-feeding bivalves. Mar Ecol Prog Ser 104: 63-75.

Kasai A, Horie H, Sakamoto W (2004) Selection of food sources by Ruditapes philippinarum and Mactra veneriformis (Bivalva: Mollusca) determined from stable isotope analysis. Fish Sci 70: 11-20.

Kingston MB, Gough JS (2009) Vertical migration of a mixedspecies euglena (euglenophyta) assemblage inhabiting the highintertidal sands of Nye Beach, Oregon. J Phycol 45: 10211029.

Komorita T, Kajihara R, Tsutsumi H, Shibanuma S, Yamada 
T, Higaki N, Montani S (2010) Reevaluation of the nutrient mineralization process by infaunal bivalves (Ruditapes philippinarum) in a shallow lagoon in Hokkaido, Japan. J Exp Mar Biol Ecol 383: 8-16.

Lathja K, Michener RH (1994) Stable isotopes in ecology and environmental science. Blackwell, Oxford, $316 \mathrm{pp}$.

Lorenzen CJ (1967) Determination of chlorophyll and pheopigments: spectrophotometric equations. Limnol Oceanogr 12: 343-346.

Lucas CH (2003) Observations of resuspended diatoms in the turbid tidal edge. J Sea Res 50: 301-308.

Lucas CH, Widdows J, Brinsley MD, Salkeld PN, Herman PMJ (2000) Benthic-pelagic exchange of microalgae at a tidal flat. 1. Pigment analysis. Mar Ecol Prog Ser 196: 59-73.

MacIntyre HL, Geider RJ, Miller DC (1996) Microphytobenthos: the ecological role of the iSecret Gardenî of unvegetated, shallowwater marine habitats. I. Distribution, abundance and primary production. Estuaries 19: 186-201.

Montani S, Magni P, Abe N (2003) Seasonal and interannual patterns of intertidal microphyto- benthos in combination with laboratory and areal production estimates. Mar Ecol Prog Ser 249: 79-91.

Oviatt CA, Nixon SW (1975) Sediment resuspension and deposition in Narragansett Bay. Estuar Coast Mar Sci 3: 201-217.

Palmer JD (1960) The role of moisture and illumination on the expression of rhythmic behavior of the diatom Hantzschia amphioxys. Biol Bull 119: 330.

Parsons TR, Maita Y, Lalli CM (1984) A manual of chemical and biological methods for seawater analysis. Pergamon Press, Oxford, $184 \mathrm{pp}$.

Paterson DM (1986) The migratory behavior of diatom assemblages in a laboratory tidal micro- ecosystem examined by low temperature scanning electron microscopy. Diat Res 1: 227-
239.

Perkins EF (1958) The diurnal rhythm of the littoral diatoms of the River Eden Estuary, Fife. J Ecol 48: 725-728.

Phillips DL, Newsome SD, Gregg JW (2005) Combining sources in stable isotope mixing models: alternative methods. Oecologia 144: 520-527.

Rosa F, Bloesch J, Rathke DE (1991) Sampling the settling and suspended particulate matter (SPM). In: Handbook of techniques for aquatic sediments sampling (ed Mudroch A, MacKnight SD). CRC Press, Boca Raton, pp. 97-130.

Shaffer GP, Sullivan MJ (1988) Water column productivity attributable to displaced benthic diatoms in well-mixed shallow estuaries. J Phycol 24: 132-140.

Suga N, Shibanuma S, Yamada T, Higaki N, Montani S (2011) Physical structure and origin of nutrients in Hichirippu-numa (subarctic brackish lagoon). J Oceanogr Soc Japan 20: 19-36. (in Japanese with English abstract)

Yamaguchi H, Montani S, Tsutsumi H, Hamada K, Ueda N (2003) Estimation of particulate organic carbon flux in relation to photosynthetic production in a shallow coastal area in the Seto Inland Sea. Mar Pollut Bull 47: 18-24.

Yamaguchi H, Tsutsumi H, Tsukuda M, Shibanuma S, Yamada T, Montani S (2006) Utilization of food sources by benthic suspension feeding bivalves in shallow coastal areas. Jpn J Benthol 61: 59-65. (in Japanese with English abstract)

Yamaguchi H, Yoshino H, Fukumori K, Montani S (2009) Progress in the Research of Microphytobenthos Assemblages in the Seto Inland Sea Ecosystem (Symposium: Environment of Coral Reef and surrounding coastal area). Bull Coast Oceanogr 47: 19-27. (in Japanese with English abstract)

Young DK (1971) Effects of infauna on the sediment and seston of a subtidal environment. Vie et Milieu 22: 557-571. 